\title{
Modeling and simulation analysis of wind - hydro hybrid power plant
}

\author{
Xue-Jia Huang ${ }^{1}$; Neng-Sheng Bao ${ }^{2}$ \\ ${ }^{1}$ Shantou Polytechnic; \\ ${ }^{2}$ College of Engineering, Shantou University \\ Shantou, Guangdong, China \\ E-mail:xjhuang@stu.edu.cn
}

\begin{abstract}
In order to study the influence of wind - hydro hybrid power plant on power grid, the paper represents the method of wind - hydro hybrid power plant, a simulation model combined wind turbine system, hybrid power system with electrical network, SVC, PSS and large hydro power plant was built by Matlab/Simulink. It was suffered under both situations of static and dynamic simulation with using wind speed data which from the fact wind farm. The simulation results validate the power grid can maintain stability after the wind - hydro hybrid power plant is connected with the network. As a consequence, the results will provide technical basis for how to increase the position of wind turbine system in energy supply system.
\end{abstract}

Keywords: Hybrid Power Plant; Wind Turbine System; Water Turbine Power Station; Dynamic Simulation; Stability Analysis.

\section{Introduction}

Wind energy has characteristics like randomness, intermittency and seasonality. As a result, output fluctuation of the power station is huge, the security and stability of power grid are seriously weakened. Therefore, it is a problem that should be solved urgently to make wind generator system output stable power to power grid via reasonable methods and to increase the proportion of power grid capacity occupied by wind power through improvement of the power grid structure [1].

In order to solve the continuity and stability problems of wind power, we need a hybrid system. Multi - energy hybrid system (such as wind - gas turbine hybrid plant, wind - diesel engine hybrid plant, wind - high-temperature fuel cell hybrid plant, etc.) are proposed at home and abroad. The start and grid connection time of hydroelectric power plant is short, and the operation and dispatching are flexible. Hence it can adapt to the output change of wind power station triggered by the change of wind speed. Rapid start and stop can be realized when it is combined with wind power plant. Thus the entire hybrid power system can realize a stable output, which will thoroughly solve the adverse effect of wind power station load fluctuation on network voltage and frequency caused by the randomness and volatility of wind flow speed 
during large-scale development of wind power [2].

The whole-system model of wind-hydro hybrid power plant mainly includes two subsystems: wind turbine system and hydro-generator system models. Based on the previous researches [3-5], this paper puts forward the power plant method of combining wind turbine with water turbine. Moreover, through a series of modeling and simulation on Matlab/Simulink platform, it has verified that the hybrid power system can enhance stability of wind power station when it outputs to power grid.

\section{Wind Power Station Model}

The model of wind power station only considers the whole-system model of wind power station comprising pneumatic system, rotor, electric generator and control system; other relevant power grid, cable, capacitor bank, transformer and breaker models will be directly called in the standard library of Matlab/Simulink. The whole-system model of active stall wind power station is as follows [3-5]:

$$
\begin{gathered}
\left\{\begin{array}{c}
\frac{d \bar{E}^{\prime}}{d t}=-j s \omega_{s} \bar{E}^{\prime}-\frac{1}{T_{0}^{\prime}}\left(\bar{E}^{\prime}-j\left(X-X^{\prime}\right) \bar{I}_{s}\right) \\
\overline{V_{s}}-\bar{E}^{\prime}=\left(R_{s}+j X^{\prime}\right) \bar{I}_{s}
\end{array}\right. \\
2 H \frac{d s}{d t}=T_{r}-T_{D}-T_{e} \\
T_{r}=\frac{C_{p}(\lambda, \beta) \cdot \frac{1}{2} \rho \pi R^{2} \cdot V^{3}}{\omega_{r} T_{r 0}} \\
T_{D}=\frac{C_{D} \omega_{r}}{T_{r 0}}=K_{D} \omega_{r} \\
T_{e}=E_{q}^{\prime} i_{s q}+E_{d}^{\prime} i_{s d} \\
\beta=\frac{1}{T_{\beta}}\left(\beta_{r}-\beta\right) \\
\beta_{r}=\left\{\begin{array}{c}
K_{P}\left(P_{e}-P_{e B}\right)+K_{I} \int\left(P_{e}-P_{e B}\right) d t \quad \begin{array}{l}
P_{e} \geq P_{e B} \\
0
\end{array} \\
P_{e}<P_{e B}
\end{array}\right.
\end{gathered}
$$

In the above model, $\boldsymbol{C p}(\lambda, \boldsymbol{\beta})$ means the power coefficient; $\boldsymbol{T r}$ refers to the wind wheel torque; $\rho$ indicates the air density; $\mathrm{R}$ denotes the wind wheel radius; $\mathrm{V}$ signifies the effective wind speed; $\lambda$ represents the tip speed ratio; $\beta$ means the pitch angle; $\omega r$ 
is the wind wheel rotation speed; $\boldsymbol{T} \boldsymbol{\beta}$ refers to the time constant of pitch angle actuator; $\boldsymbol{T r} 0$ denotes the wind wheel torque under rated conditions; $\boldsymbol{T r}$ indicates the impeller torque; $\boldsymbol{T D}$ signifies the damping torque; $\boldsymbol{T e}$ means the electro-magnetic torque of generator; $\mathrm{H}$ represents the time constant of machine set; $\omega s$ is the synchronous speed of generator; s refers to the slip ratio; $\boldsymbol{V} \boldsymbol{s}$ signifies the asynchronous generator stator voltage; $E^{\prime}$ means the equivalent transient potential of asynchronous generator; Is denotes the stator current; $\boldsymbol{R} \boldsymbol{s}$ indicates the stator resistance; $\boldsymbol{R} \boldsymbol{r}$ refers to the rotor resistance; $\mathrm{X}$ denotes the synchronous reactance; $X^{\prime}$ represents the equivalent transient reactance of asynchronous generator; $T_{0}^{\prime}$ is the time constant of rotor winding in open circuit of stator winding. $\bar{E}^{\prime}, \bar{V}_{s}$ and $\bar{I}_{s}$ are corresponding complex variables: $\bar{E}^{\prime}=E_{q}^{\prime}+j E_{d}^{\prime}, \bar{V}_{s}=V_{s q}+j V_{s d}$ and $\bar{I}_{s}=I_{s q}+j I_{s d}$. Major parameters are as follows: $\boldsymbol{X} \boldsymbol{s}=\boldsymbol{L} \boldsymbol{s} \boldsymbol{\omega} \boldsymbol{s}$ refers to the stator reactance; $\boldsymbol{X} \boldsymbol{r}=\boldsymbol{L} \boldsymbol{r} \boldsymbol{\omega} \boldsymbol{s}$ means the rotor reactance; $\boldsymbol{X} \boldsymbol{m}=\boldsymbol{L} \boldsymbol{r} \boldsymbol{s} \boldsymbol{\omega} \boldsymbol{s}$ signifies the mutual reactance between stator and rotor; $\boldsymbol{L s}$ represents the magnetic flux leakage self-inductance coefficient of stator phase winding; $\boldsymbol{L r}$ indicates the magnetic flux leakage self-inductance coefficient of rotor phase winding; Lrs denotes the mutual inductance coefficient of stator and rotor winding.

\section{Simulation Model of Water Turbine Power Station}

Water turbine model is often represented with complicated time-varying nonlinear systems. The model of water turbine and governor in Matlab are shown in Figure 1. It is composed of a nonlinear water turbine model, a PID management system and a servo motor (an engine to control the operation of mechanical components in servo system, and an indirect gear change mechanism supplementing the motor) [6-7].

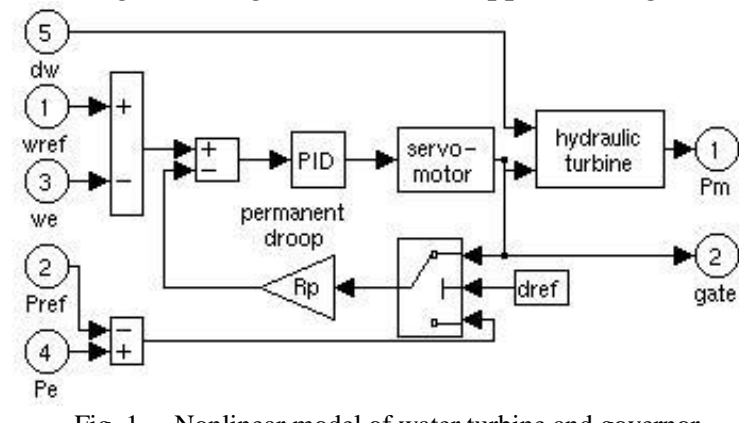

Fig. 1. Nonlinear model of water turbine and governor

In order to guarantee universality of the research, we have selected a typical electric power system, synchronous machine and excitation system are used to simulate the generator system; transformer (T), electric transmission line (Line), load (Load), standard voltage source (source) and measurement elements are used to simulate the infinite-bus power system. 


\section{Wind-Hydro Hybrid Power Plant Model}

Wind-hydro hybrid power plant model adopts the principle of compound use dominated by new energy (wind energy) utilization as the main part of base load, and supplemented by conventional energy (hydro-energy) as the complementary part of base load and top-load, as shown in Figure 2.

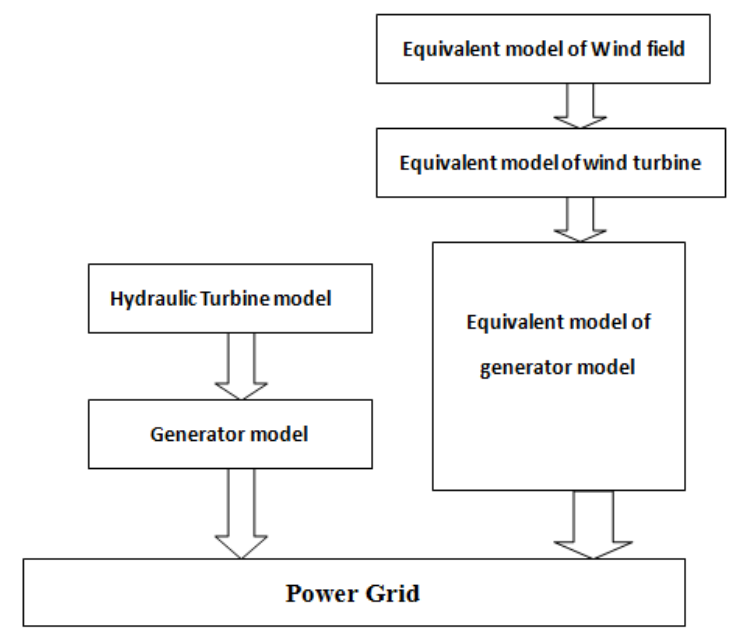

Fig. 2. Schematic diagram of wind-hydro hybrid power plant model

Specifically speaking, the ratio between capacity of wind power plant and capacity of water turbine is about 4:3. In another word, wind power plant takes up $57 \%$ of the capacity and water turbine occupies $43 \%$ of the capacity. Such capacity proportion is based on the practice starting from investment optimization. The steam turbine in water turbine power plant is composed of a water turbine with the power of 1.2 million kilowatts. Wind power plant in wind turbine system comprises 80 wind turbine arrays with the capacity of $2 \mathrm{MW}$. There are 8 rows and each row contains 10 sets.

\subsection{Wind power plant model}

10 wind turbines in each row are equated to one set via equivalence principle. After processing with such method, the 80 wind turbines in the whole wind power plant can be replaced with 8 equivalent machines.

Meanwhile, in order to make the study convenient, gives some hypotheses and explanations to the wind conditions.

(1) During the simulation period, the wind direction remains unchanged. In another word, the wind direction is always perpendicular to the wind wheel rotation plane of each wind turbine. 
(2) The 10 wind turbines acting on the same row have the same wind speed. As shown in the figure, wind speed in the first row is Wind1, wind speed in the second row is Wind2, and the rest can be done in the same manner. Hence wind speed in the eighth row is Wind8. Therefore, the wind condition of the eight equivalent machines after equating can be expressed with Wind 1 - Wind8.

(3) In order to increase the reliability of simulation, wind speeds Wind 1 - Wind8 in the figure are obtained after simplification treatment according to the measured wind speeds of a wind power plant in Xinjiang, so the data are real to some extent. Figure 3 presents the values of Wind 1 - Wind 8 after processing (the simulation results of $10 \mathrm{~min}$ are selected).

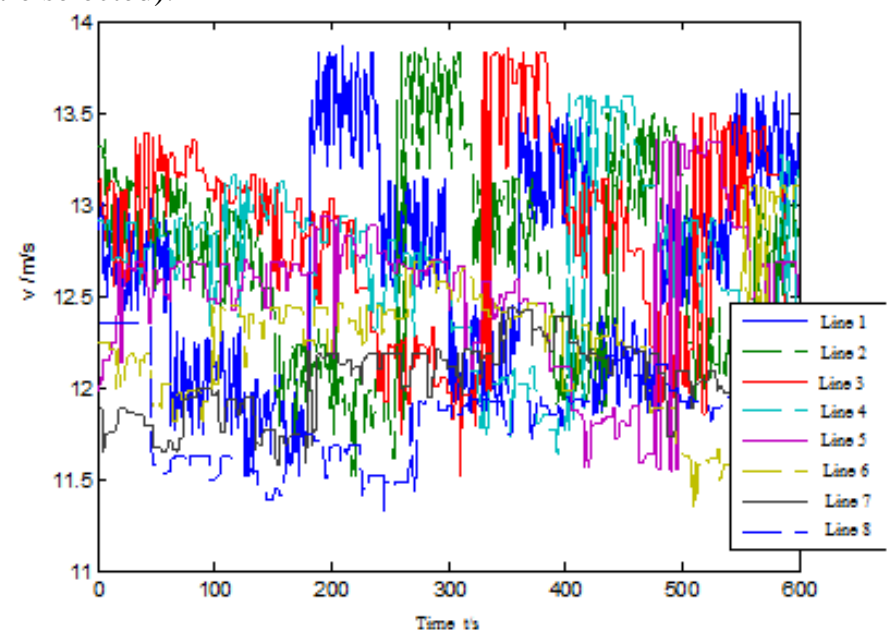

Fig. 3. Equivalent wind speed in wind farm.

\subsection{Wind turbine system model in the hybrid system}

According to the contents discussed in the previous chapters, the simulation model of wind turbine system in the hybrid system of Matlab/Simulink platform is obtained, as shown in Figure 4. 


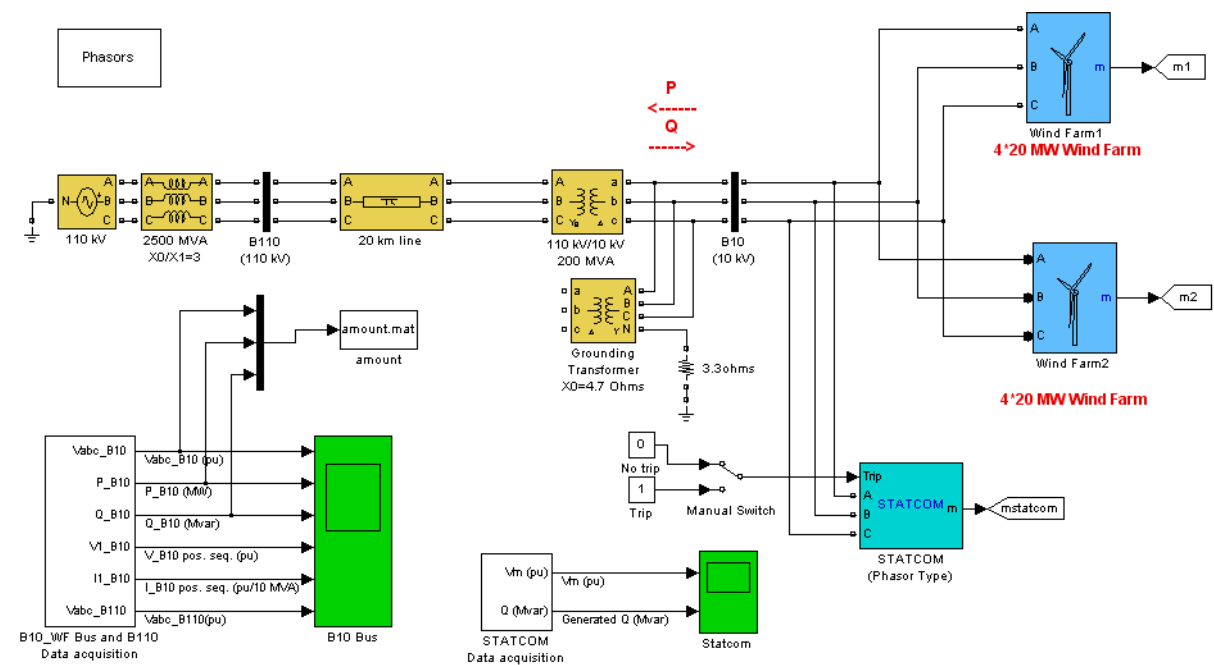

Fig. 4. Wind turbine-generator system model.

As shown in Figure 4, for convenient expression, the eight equivalent machines are installed in two modules, and each module includes four equivalent machines.

\subsection{Water turbine power plant model in the hybrid system}

According to the contents discussed in the previous chapters, the simulation model of water turbine power plant in the hybrid system of Matlab/Simulink platform is obtained, as shown in Figure 5.

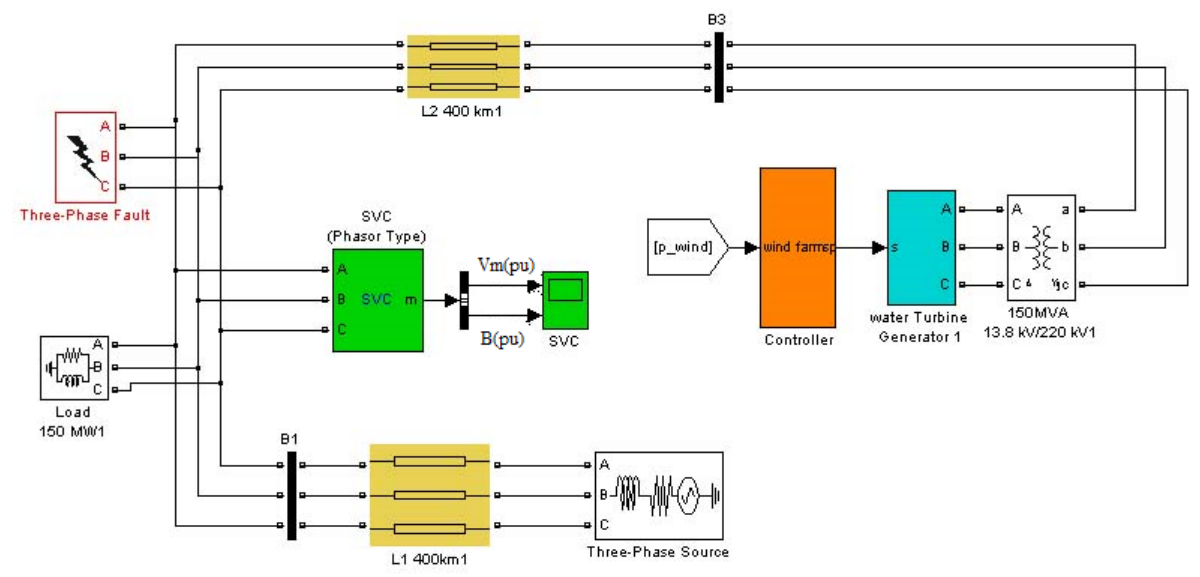

Fig. 5. Water turbine generator system model. 


\subsection{Overall model of the hybrid system}

According to the previous wind power plant model and water turbine power plant model, by combining with the stabilizing device model of power system, the overall model of wind-hydro hybrid power plant can be gained, as shown in Figure 6.

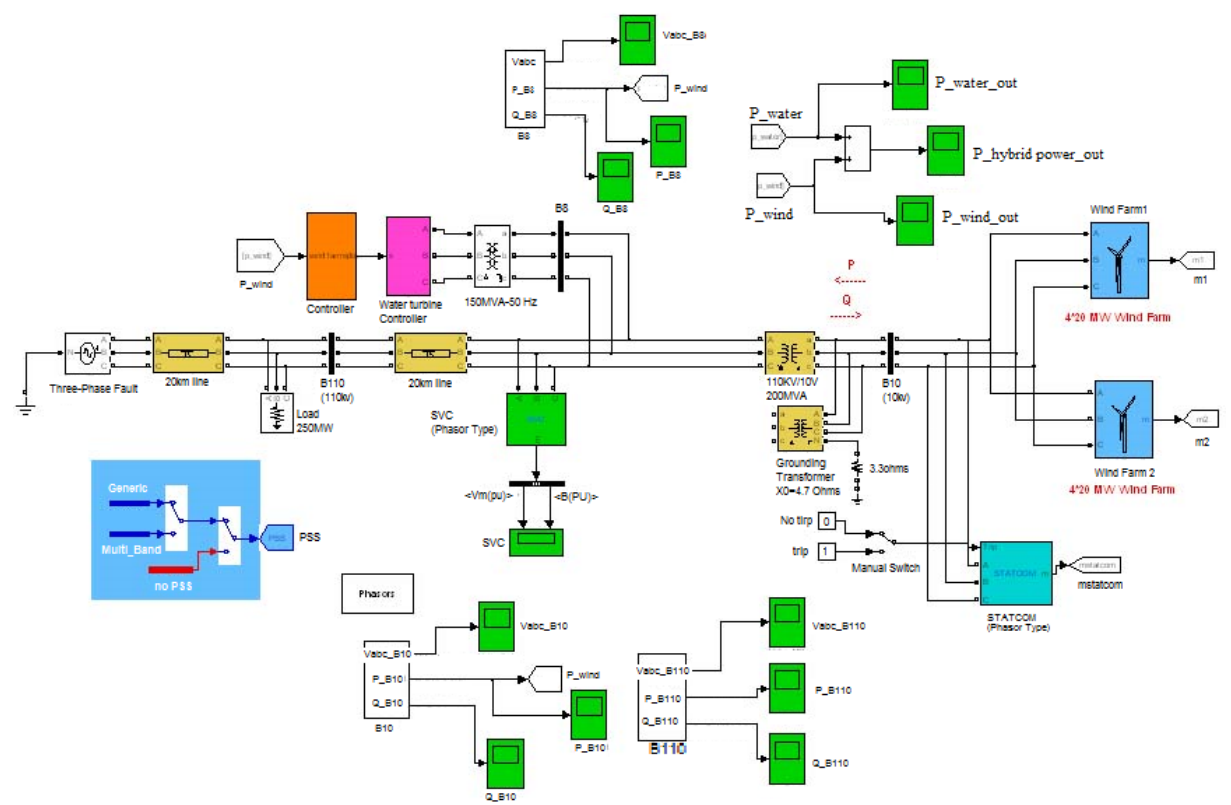

Fig. 6. The whole model of wind-hydro hybrid power plant.

\subsection{Grid connection parameter setting of wind-hydro hybrid power plant}

\subsubsection{Model selection of wind generator}

The installed capacity of the wind power plant selected is $160 \mathrm{MW}$, and the rated capacity of one machine is $2 \mathrm{MW}$. There are 60 sets in total. The specific parameters are as follows:

$\boldsymbol{P}=2 \mathrm{MW}, \quad \boldsymbol{V}=690 \mathrm{~V}, \boldsymbol{f}=20 \mathrm{~Hz}, \boldsymbol{V}=13 \mathrm{~m} / \mathrm{s}, \quad \boldsymbol{K} \boldsymbol{D}=0.01 \mathrm{pu}, \boldsymbol{K} \boldsymbol{p}=5, \quad \boldsymbol{K} \boldsymbol{I}=25, \boldsymbol{H}=3.5 \mathrm{~s}$, $\boldsymbol{R} \boldsymbol{s}=0.00488 \mathrm{pu}, \quad \boldsymbol{X} \boldsymbol{s}=0.09241 \mathrm{pu}, \quad \boldsymbol{R} \boldsymbol{r}=0.00549 \mathrm{pu}, \quad \boldsymbol{X} \boldsymbol{r}=0.09955 \mathrm{pu}, \quad \boldsymbol{X} \boldsymbol{m}=3.9527 \mathrm{pu}$, So $=-0.010$

\subsubsection{Model selection of water turbine power plant}

The installed capacity of the water turbine power plant selected is $120 \mathrm{MW}$, and the rated capacity of one machine is $120 \mathrm{MW}$. There is 1 set in total. The specific parameters are as follows:

$$
P_{n}=120 \mathrm{MV} \bullet A, V_{n}=13.8 \mathrm{kV}(\mathrm{rms}), f_{n}=50 \mathrm{~Hz}, T_{d}^{\prime}=1.01 \mathrm{~s}, T_{d}^{\prime \prime}=0.053
$$


$\mathrm{s}, T_{q o}^{\prime \prime}=0.1 \mathrm{~s}, X_{d}=1.305 \mathrm{pu}, X_{d}^{\prime}=0.296 \mathrm{pu}, X_{d}^{\prime \prime}=0.252 \mathrm{pu}, X_{q}^{\prime}=0.474 \mathrm{pu}, X_{q}^{\prime \prime}$ $=0.243 \mathrm{pu}, X_{1}=0.18 \mathrm{pu}, H=3.7 \mathrm{~s}, F_{n}=0 \mathrm{pu}$

The specific parameters of excitation system are as follows:

$K_{a}=200, T_{a}=0.001 \mathrm{~s}, K_{e}=1, T_{e}=0 \mathrm{~s}, T_{r}=20 \mathrm{e}-3 \mathrm{~s}, K_{f}=0.001, T_{f}=0.1 \mathrm{~s}$.

\subsubsection{Parameter setting of static var compensator}

SVC module in Sim Power System is applied, and parameter setting is as follows:

The rated voltage is $\mathrm{UN}=35 \mathrm{kv}$ and the reactive power limitation [Qc QL] is [-150MW 150MW].

\subsubsection{Parameter setting of power system stabilizer}

Generic PSS module is used and parameter setting is as follows:

The time constant of sensor is $30 \mathrm{e}-3$; the gain is 20 ; the stable output voltage limitation is $-15 \%, 15 \%$.

\section{Simulation Results and Analysis}

Figure 6 shows the overall model of wind-hydro hybrid power plant. According to the predicted wind speed, the predicted plant power of wind turbine is calculated. Moreover, the input flow used for hydroelectric plant is worked out according to the storage capacity level of hydropower station. Then the plant schedule about overall output power of wind-hydro hybrid power plant is made.

When the simulation time is $80 \mathrm{~s}$, the simulation results are shown in Figure 7, Figure 8, Figure 9 and Figure 10.

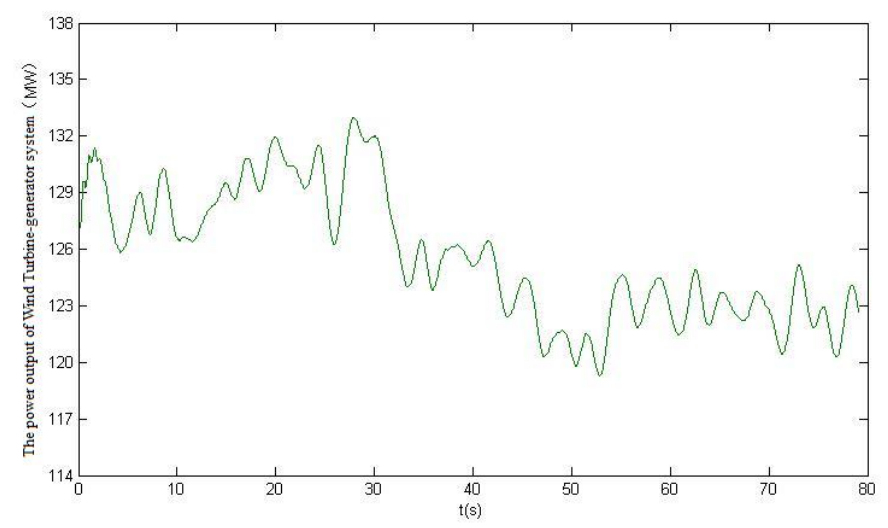

Fig. 7. The power output of Wind Turbine-generator system. 


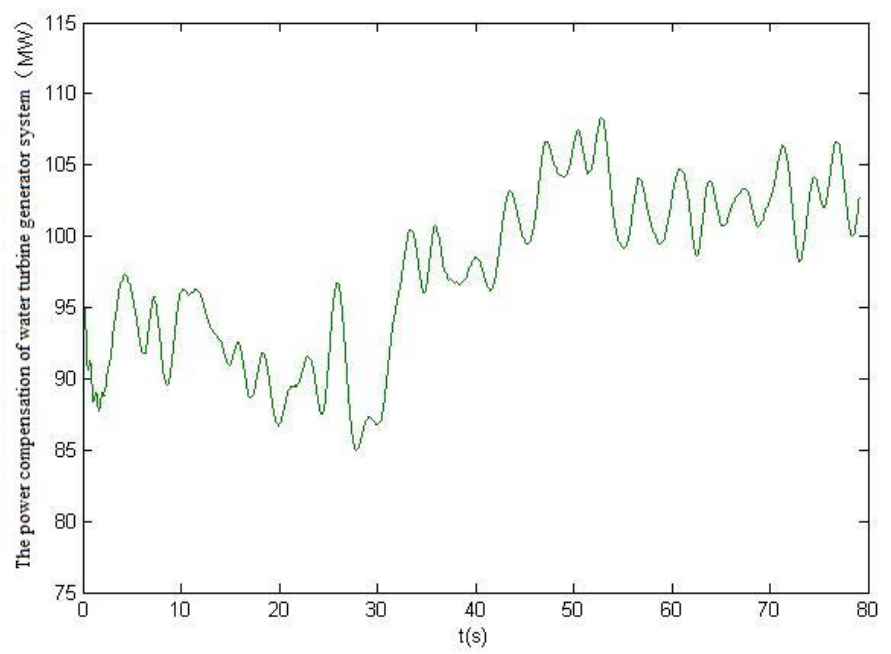

Fig. 8. The power compensation of water turbine generator system.

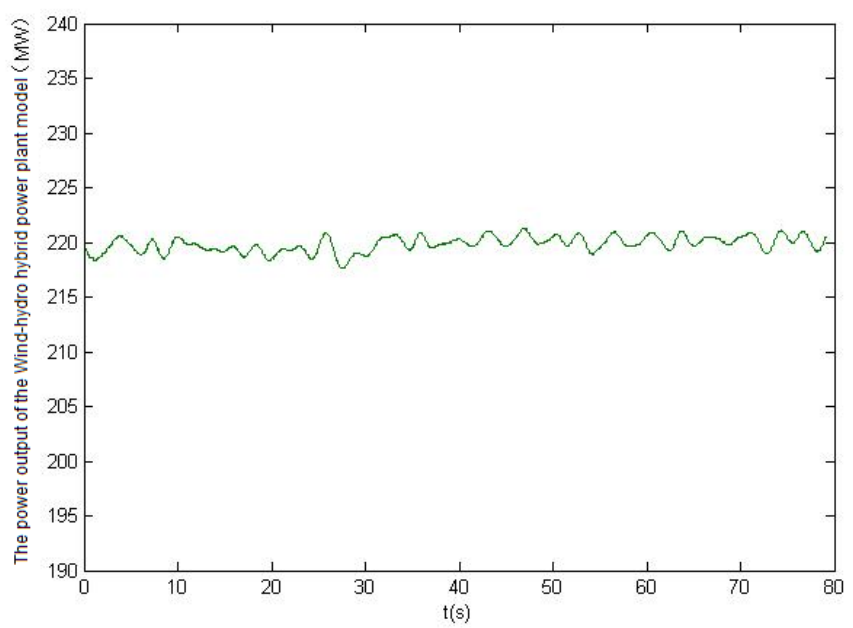

Fig. 9. The power output of the Wind-hydro hybrid power plant model. 


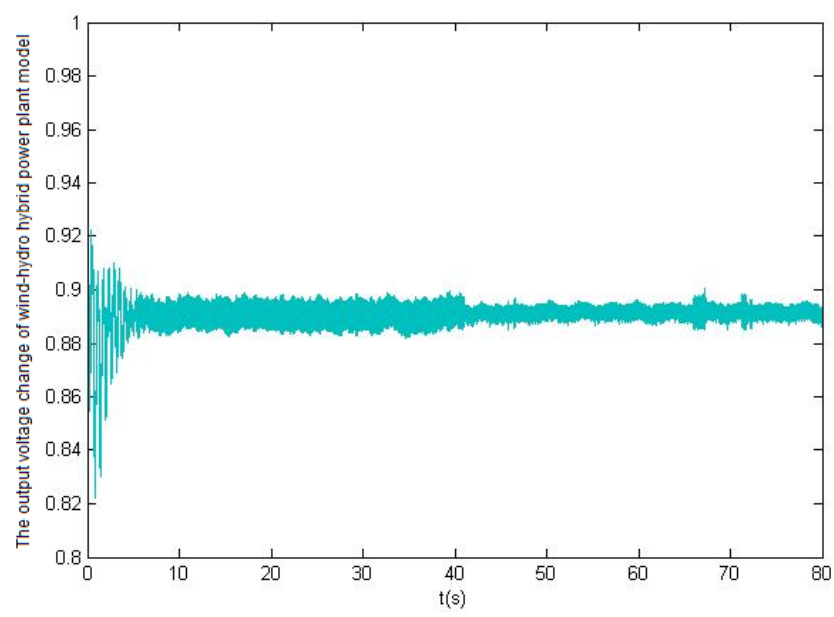

Fig. 10. The output voltage change of wind-hydro hybrid power plant model.

According to Figure 7, Figure 8 and Figure 9, if the output power of wind turbine system decreases in a short time, the compensation power of water turbine power plant will increase in a short time. If output power of wind turbine system increases in a short time, the compensation power of water turbine power plant has to decrease in a short time. Output powers of the two systems should present a complementary phenomenon in a short time, and an extremely small time difference will happen to such complementation. According to the simulation results, overall variation trends of the two curves are complementary within the simulation time. The overall output power of wind-hydro hybrid power plant can be gained by overlapping the two curves. As shown in Figure 9, this curve always stays near 220MW, and its fluctuation is small. Figure 10 reflects voltage changes of the overall model of wind-hydro hybrid power plant. Output voltage of model fluctuates slightly at the initial stage of start, but it is stabilized within an allowable fluctuation range soon. According to Figure 9 and Figure 10, we can obtain the correctness and validity of the model established.

\section{Conclusions}

The operation mechanism model of wind-hydro hybrid power plant in power grid is established by applying modules in MATLAB/SIMULINK tool cabinet, and simulation is conducted for this model through simulation environment. Response of the whole power grid system under actual wind speed disturbance is simulated. According to the results, wind-hydro hybrid power plant can operate stably when it is connected to a large-scale power grid, and this system has a very good application prospect. Through researches on this model, we can further guarantee safe, economic, reliable and stable operation of electric power system, improve the power supply 
quality of electric power system, increase the power supply reliability of electric power system, and enhance the operation initiative of electric power system. Meanwhile, a fundamental basis is provided for future studies on how to improve the status of wind generator system in the entire energy supply system.

\section{Reference}

1. Holds worth L, Charalambous I, Ekanayake J B, et al. Power system fault ri de through capabilities of induction generator based wind turbines [J]. Wind Engineering, 2004, 28(4):399-412

2. Bao Nengsheng, Hu Guangwang, Ni Weidou. Study on constitution and capacity rate of a novel hybrid wind and small gas turbine power plant system [J]. Acta Energiae Solaris Sinica, 2007, 28(2):189-195.

3. Bao Nengsheng, Zhu Ruidan, Ni Weidou. Three phase short grid fault transient analysis of wind farm installed with dfig wind turbine system [J]. Control Theory and Application, 2008, 25(1):141-144.

4. Bao Nengsheng, Xu Junping, Ni Weidou, et al. Study on dynamic characteristics of large-scale stall wind turbine system [J]. Acta Energiae Solaris Sinica, 2007, 28(12):1329-1334.

5. Xu Junping. Study on dynamic characteristics of hybrid power system combining wind farm with small gas turbine power plants [D]. Shantou University, 2007.

6. IEEE Working Group on Prime Mover and Energy Supply Models for System Dynamic Performance Studies, Hydraulic Turbine and Turbine Control Models for Dynamic Studies, IEEE Transactions on Power Systems, Vol.7, No.1, February, 1992, pp. 167-179.

7. Wang Xifan. Modern power system analysis [M].Beijing: Science Press, 2003.

8. PENG Xiyun, LIU Ruiye. Research on the frequency regulation of aidding system of VSCF double-fed wind generator [J]. Power System Protection and Control, 2011, 39(11): 56-61.

9. LIU Zhihong, LIU Mingming. Power fluctuations energy saving control mathematical modeling of the wind and hydro power complementary micro grid [J]. Power System and Clean Energy, 2015, 31(10): 123-127.

10. Brian D Vick, Tim A Moss. Adding concentrated solar power plants to wind farms to achieve a good utility electrical load match [J]. Solar Energy, 2013(92):298-312. 